\section{Revista Brasileira de Administração Científica}

Brazilian Journal of Scientific Administration

Abr a Jun 2021 - v.12 - n.2
This article is also available online at: www.sustenere.co

\title{
Qualidade de vida entre docentes do ensino superior: contribuições para a promoção da saúde do trabalhador
}

Para compreender o nível de qualidade de vida de um indivíduo, faz-se necessário conhecê-lo em sua totalidade, avaliando fatores internos e externos que atuam sobre o sujeito. Neste sentido, a variável trabalho exerce grande influência, pois em alguns casos relaciona-se intrinsicamente com a identidade do ser, como ocorre no trabalho docente. Este estudo observacional, descritivo, de corte transversal e abordagem quantitativa, teve como objetivo identificar o nível de qualidade de vida de docentes de diferentes modalidades de ensino. A amostra foi composta por 79 professores de uma instituição de ensino superior privada localizada em Valença/RJ que responderam a um questionário composto por duas partes: caracterização dos respondentes e identificação do nível de qualidade de vida, este obtido por meio do instrumento genérico de avaliação da qualidade de vida SF-36, dividido em oito domínios. Para análise dos dados, utilizou-se a estatística descritiva, com determinação de frequência, média e desvio padrão e os resultados apresentados por meio de gráficos e tabelas. Observou-se que os docentes que atuam na modalidade presencial e EaD possuem os domínios Capacidade Funcional, Limitações por Aspectos Físicos, Dor, Estado Geral de Saúde e Vitalidade com médias superiores àqueles que lecionam exclusivamente na modalidade presencial, os quais, por sua vez, apresentaram os fatores Aspectos Sociais, Limitações por Aspectos Emocionais e Saúde Mental com valores de médias superiores quando comparado os dois grupos. Diante dos resultados, a instituição deve desenvolver e aplicar ações que potencializem a qualidade de vida desses profissionais.

Palavras-chave: Docentes; Ensino Superior; Qualidade de Vida; Questionário SF-36; Trabalho Docente.

\section{Quality of life among higher education teachers: contributions to promoting worker health}

\begin{abstract}
To understand the level of quality of life of an individual, it is necessary to know him in his entirety, evaluating internal and external factors that act on the subject. In this sense, the work variable has a great influence, because in some cases it is intrinsically related to the identity of the being, as occurs in teaching work. This observational and descriptive cross-sectional study with a quantitative approach aimed to identify the level of quality of life of teachers from different teaching modalities. The sample consisted of 79 professors from a private higher education institution located in Valença/RJ who answered a questionnaire composed of two parts: characterization of respondents and identification of the level of quality of life, obtained through the generic instrument for assessing quality of life, SF36 , divided into eight domains. For data analysis, descriptive statistics were used, with determination of frequency, mean and standard deviation and the results presented through graphs and tables. It was observed that professors who work in the face-to-face and distance education modality have for the domains of Functional Capacity, Limitations due to Physical Aspects, Pain, General Health and Vitality, averages higher than those who teach exclusively in the face-to-face modality, who in turn present higher mean values for the factors of Social Aspects, Limitations due to Emotional Aspects and Mental Health when comparing the two groups. In view of the results, the institution must develop and apply actions that enhance the quality of life of these professionals.
\end{abstract}

Keywords: Teachers; University Education; Quality of Life; SF-36 Questionnaire; Teaching Work.

\section{Topic: Recursos Humanos}

Reviewed anonymously in the process of blind peer.
Received: 07/04/2021

Approved: 04/06/2021

Júlio Cesar da Silva (iD

Centro Universitário de Valença, Brasil

http://lattes.cnpq.br/4798378456913301

http://orcid.org/0000-0002-6132-1452

rh.jcesar@gmail.com

Carlos Antonio da Silva Carvalho (iD)

Centro Universitário de Valença, Brasil

http://lattes.cnpq.br/0064729090277762

http://orcid.org/0000-0002-2048-022X

carlos.carvalho@faa.edu.br

Referencing this:

SILVA, J. C.; CARVALHO, C. A. S.. Qualidade de vida entre docentes do ensino superior: contribuições para a promoção da saúde do trabalhador. Revista Brasileira de Administração Científica, v.12, n.2, p.39-54, 2021. DOI: http://doi.org/10.6008/CBPC2179684X.2021.002.0004 


\section{INTRODUÇÃO}

Nos últimos anos, as organizações têm dispensado um papel de destaque às pessoas, pois é por meio delas que os objetivos organizacionais são atingidos (CHIAVENATO, 2015). Porém, para alcançar as metas desejadas, é necessário que os colaboradores possuam, dentre outros fatores, um nível de qualidade de vida satisfatório, aqui compreendido não apenas como a ausência de doenças ou enfermidades, mas um estado de completo bem-estar físico, mental e social.

Esse equilíbrio, conforme explicam Vasconcelos et al. (2012), é desejado por todos os trabalhadores, que além de buscá-lo no lado pessoal, o associa ao trabalho, uma vez que grande parte do tempo do indivíduo é vivenciado dentro das organizações, desenvolvendo suas atividades laborais. Sendo assim, toda empresa deve adotar medidas e/ou iniciativas que proporcionem qualidade de vida aos funcionários, para que estes atendam às necessidades e expectativas das instituições com êxito, bem como seus próprios interesses.

Nessa perspectiva, faz-se necessário, nos dias atuais, buscar compreender o sentido e a abrangência dispensados à qualidade de vida, de modo a obter o desenvolvimento de relações saudáveis com o trabalho e, em geral, com a vida (CURY JUNIOR, 2010), principalmente quando a atividade laboral desempenha papel de destaque na construção da identidade do sujeito, como ocorre no trabalho docente (PEREIRA, 2006).

Além de influenciar a identidade do indivíduo, o trabalho docente pode interferir de forma significativa na qualidade de vida daqueles que exercem a profissão. Estudos realizados com professores que atuam no nível superior indicam que fatores relacionados ao ambiente de trabalho (ARAÚJO et al., 2019) e a particularidades da profissão docente (SANCHEZ et al., 2019), em sua grande maioria, prejudicam a obtenção de um nível de qualidade de vida satisfatório, o que exige, portanto, um olhar diferenciado sobre esta classe trabalhadora.

Diante da importância dada à qualidade de vida para o alcance dos objetivos organizacionais, à existência de uma relação intrínseca entre trabalho e identidade pessoal e ao fato de que características do ambiente de trabalho e particularidades da profissão afetam de forma negativa o nível de qualidade de vida daqueles que exercem à docência, o problema de pesquisa central deste estudo pode ser expresso na seguinte pergunta: "Qual é o nível de qualidade de vida de docentes do ensino superior que atuam em um centro universitário?".

Considerando que o trabalho docente pode ser realizado em diferentes modalidades de ensino, a saber, presencial, a distância (EAD) e semipresencial (presencial e EAD), assume-se como hipótese preliminar que professores que atuam simultaneamente nas modalidades presencial e EAD possuem nível de qualidade de vida, em geral, menor do que aqueles que atuam apenas em uma modalidade (presencial ou EAD).

A pesquisa tem como objetivo geral identificar o nível de qualidade de vida de docentes de um centro universitário. Associado ao objetivo geral, tem-se como proposta de objetivos específicos: determinar o perfil sociodemográfico dos investigados; conhecer o nível de qualidade de vida dos docentes das modalidades presencial, EAD e semipresencial (presencial e EAD); comparar o nível de qualidade de vida dos docentes de acordo com a modalidade de ensino que atuam e apontar lacunas a serem preenchidas para garantir a 
promoção da saúde desses profissionais.

A realização deste estudo se justifica por investigar e avaliar o nível de qualidade de vida de docentes do ensino superior, identificando, a partir dos resultados, a necessidade de estabelecer ações para promover a saúde desses profissionais que atuam diariamente no processo de ensino-aprendizagem de futuros profissionais e, portanto, precisam gozar de qualidade de vida para alcançar os resultados esperados decorrentes do processo de ensino.

Para alcançar os objetivos desejados, este estudo apresenta, além desta introdução, as seguintes seções: fundamentação teórica, na qual se discute qualidade de vida e trabalho docente; materiais e métodos, com o delineamento da metodologia empregada; resultados e discussão, com a apresentação e análise dos dados; considerações finais e, por último, referencial teórico utilizado.

\section{REVISÃO TEÓRICA}

\section{Qualidade de Vida}

Quando o assunto é qualidade de vida, a literatura especializada destaca sua relevância social e científica, embora o tema apresente uma grande imprecisão conceitual, o que prejudica a investigação, o diálogo entre áreas do saber que pesquisam o assunto e, sobretudo, a aplicação do conhecimento que é produzido em prol da melhoria da qualidade de vida da população (PEREIRA et al., 2012).

Para Day et al. (1996, citado por PEREIRA et al., 2012), os estudos sobre qualidade de vida podem ser classificados de acordo com quatro abordagens gerais: econômica, psicológica, biomédica e geral ou holística. As duas primeiras abordagens visam, respectivamente, indicadores sociais como principais elementos e indicadores subjetivos dos indivíduos relacionados a sua vivência, desconsiderando o contexto ambiental (DAY et al., 1996, citado por PEREIRA et al., 2012).

A abordagem médica (MINAYO et al., 2000) foca a capacidade de viver sem doenças ou de superar as dificuldades que estas impõem. Nesta abordagem, verifica-se a tendência de utilizar saúde e qualidade de vida como sinônimos. No entanto, embora sejam conceitos que apresentam uma grande relação entre si, cada um possui suas particularidades (PEREIRA et al., 2012).

Por último, a abordagem geral ou holística entende que o conceito de qualidade de vida é multidimensional, seus componentes organizam-se de forma complexa e dinâmica e difere de pessoa para pessoa conforme o ambiente/contexto que a envolve, sendo observadas até mesmo diferenças entre indivíduos inseridos em um ambiente similar (RENWICK et al., 1996, citado por PEREIRA et al., 2012). Ainda de acordo com os autores, nesta abordagem não é uma boa saúde que garante qualidade de vida, mas sim o contrário.

Aproximando-se da abordagem geral ou holística, o conceito atual de qualidade de vida mais difundido é o da Organização Mundial da Saúde (OMS), entendido como "a percepção do indivíduo de sua inserção na vida, contexto da cultura e sistemas de valores nos quais ele vive e em relação aos seus objetivos, expectativas, padrões e preocupações" (WHO, 1995). 
Sendo assim, para a OMS, o conceito de qualidade de vida engloba o bem-estar espiritual, físico, mental, psicológico e emocional, bem como os relacionamentos sociais (família e amigos), saúde, educação, condições de habitação, saneamento básico e outros fatores (WHO, 1995). Em suma, para ter qualidade de vida, o homem deve ser considerado em sua totalidade.

Levando em consideração o conceito proposto pela OMS, Mattos et al. (2017) pontuam que a qualidade de vida "assume uma dimensão pessoal e, portanto, variada, sendo subordinada às expectativas, projetos de vida e oportunidades percebidas no âmbito pessoal" e, por isso, conforme mencionam Gomes et al. (2017), varia de pessoa para pessoa, pois cada um possui objetivos, perspectivas e projetos de vida diferenciados.

Contudo, mesmo diante das especificidades individuais, pode-se dizer que a qualidade de vida de uma pessoa também mantém relação com o grau de satisfação que está possui com seu trabalho e com as demais variáveis envolvidas em sua atividade ocupacional (GOMES et al., 2017), estabelecendo uma ligação intrínseca entre condições de trabalho e saúde (SANCHEZ et al., 2019), uma vez que para determinar a qualidade de vida de um sujeito, este deve receber um olhar holístico (WHO, 1995).

\section{Trabalho Docente}

Para compreender a saúde das pessoas e populações na sociedade contemporânea (DEJOURS, 1992), é preciso atentar-se à categoria trabalho, pois está aparenta representar um papel de destaque nesse processo. Rêgo et al. (2017) destacam que o ambiente de trabalho foi remodelado no decorrer do processo histórico, resultado das intensas transformações digitais ocorridas. Essas mudanças, segundo os autores, influenciaram de forma significativa a saúde dos profissionais, principalmente daqueles que atuam na docência.

Além dessas mudanças, deve-se considerar o trabalho parte fundamental na construção da identidade do sujeito, como se observa na profissão docente, uma vez que esta demanda uma intensa relação diária do professor com a sociedade, a instituição e os alunos (PEREIRA, 2006).

Araújo et al. (2019), neste sentido, observam que o ambiente universitário pode ser identificado como gerador de fatores desgastantes quando se considera o conceito de qualidade de vida. Isso porque o trabalho docente demanda dedicação, não se restringindo apenas em ministrar aulas, mas também abordando tarefas como correção de provas, preparo de aulas, feedback e constantes atualizações, conforme elencam Ferreira et al. (2015).

A tal entendimento, somam-se as palavras de Sanchez et al. (2019), para os quais o trabalho docente, em um nível mais complexo, requer uma atuação reflexiva, crítica e competente, o que leva à necessidade de uma preparação/capacitação didática. Corroborando os autores, Bosi (2007) pontua que ao professor cabe a intensa busca pela produção acadêmica, o que contribui para a precarização da docência, pois a avaliação do profissional é feita pelo quantitativo do que produz e não pela qualidade do que é produzido.

Incrementando o assunto, Gomes et al. (2017), observam que a qualidade de vida dos professores pode ser afetada de forma negativa por diversos fatores relacionados ao trabalho docente, tais como 
[...] condições físicas e instalações inadequadas e deficitárias, falta de recursos didáticos, excesso de funções burocráticas, normas e procedimentos administrativos inadequados, interrupções durante as aulas, remuneração insuficiente, longas jornadas de trabalho, falta de reconhecimento e desvalorização profissional, ausência de plano de carreira, entre outros.

Soma-se a esses fatores, a possibilidade de um intenso desgaste cognitivo resultante do trabalho docente (ARAÚJO et al., 2019), uma vez que os profissionais podem ser submetidos a jornadas de trabalho de 40 horas semanais, além de terem que dispor de tempo para participarem de atividades extraclasse e burocráticas, bem como de atividades de pesquisa e extensão

Já Lima et al. (2009) acrescentam que o trabalho docente pode atuar como um limitante do tempo disponível para atividades pessoais. De acordo com os autores, muitas tarefas do ambiente de trabalho são levadas para serem realizadas no lar, o que acontece em momentos que, teoricamente, deveriam ser destinados ao descanso e lazer, a exemplo dos finais de semana, feriados e férias letivas. Essa ação compromete, no entendimento de Reis (2013), os momentos de lazer e de cuidados com a saúde.

Diante do postulado pela OMS em relação à definição do conceito de qualidade de vida, percebe-se que o trabalho docente possui, quando analisado em um contexto geral e específico, particularidades que o classifica como um fator influente no nível de qualidade de vida dos profissionais que exercem suas atividades no âmbito da docência, principalmente na de nível superior, o que demonstra a importância de se relacionar as variáveis qualidade de vida e trabalho docente para a compreensão do fenômeno.

\section{MATERIAIS E MÉTODOS}

Trata-se de um estudo observacional, descritivo, de corte transversal e abordagem quantitativa, realizado em uma instituição de ensino privada localizada no município de Valença-RJ.

Para Hochman et al. (2005), o estudo observacional é conduzido sem interferência do pesquisador, sendo transversal quando é realizado em um determinado instante do tempo. A pesquisa descritiva (GIL, 2018) visa descrever as características de uma determinada população em relação a uma questão estabelecida, aqui identificada como o nível de qualidade de vida dos sujeitos investigados. Por fim, a abordagem quantitativa permite, por meio de recursos e de técnicas estatísticas (MATIAS-PEREIRA, 2012), mensurar numericamente opiniões e informações.

O presente estudo foi aprovado pelo Comitê de Ética em Pesquisa (CEP), respeitando os preceitos éticos de pesquisa envolvendo seres humanos, pelo parecer $n$ ㅇ 4. 301.184. A participação de todos os voluntários ocorreu após a assinatura do Termo de Consentimento Livre e Esclarecido (TCLE).

A população do estudo foi representada por docentes que atuam em um centro universitário no município de Valença/RJ, sendo a amostra do tipo não probabilística, definida pelo critério de acessibilidade. Nessa técnica, os entrevistados são escolhidos pela disponibilidade em participar do estudo (MATIASPEREIRA, 2012). As amostras não probabilísticas restringem os resultados à amostra analisada (MATTOS et al., 2017), o que impede que os resultados sejam estendidos à população. O contato com os professores e o convite para participar do estudo foram realizados por meio do envio de mensagens pelos diretores de cada curso da instituição, após solicitação dos pesquisadores. A amostra final foi composta por 79 docentes que 
aceitaram participar do estudo, após assinarem o TCLE.

A coleta de dados foi realizada no período compreendido entre outubro e novembro de 2020, via email, utilizando o Google Forms. Para tanto, adotou-se um instrumento formado por duas seções. A primeira, reunia informações para caracterização da amostra e, a segunda, para identificar o nível de qualidade de vida dos investigados.

Sexo, idade, estado civil, titulação, tempo de serviço, exclusividade de atuação, regime de horário, área de conhecimento, modalidade de ensino e percepção do nível de qualidade de vida constituíram as variáveis da primeira seção. Para avaliar o nível de qualidade de vida, segunda parte, utilizou-se o Questionário SF-36 (Short Form Health Survey 36) (Questionário A), traduzido e validado para a realidade brasileira por Ciconelli (1997).

\section{Questionário A: SF-36 (CICONELLI, 1997)}

Instruções: A seguir, você encontrará 11 questões que tem como objetivo avaliar seu nível de qualidade de vida. Responda a cada questão considerando sua situação atual. Para cada pergunta/item, responda de acordo com a escala fornecida. Por exemplo, na questão número 1, se em geral você diria que sua saúde é boa, marque o número 3 .

1- Em geral você diria que sua saúde é:

\begin{tabular}{|l|l|l|l|l|}
\hline Excelente & Muito Boa & Boa & Ruim & Muito Ruim \\
\hline 1 & 2 & 3 & 4 & 5 \\
\hline
\end{tabular}

2- Comparada há um ano atrás, como você se classificaria sua saúde em geral, agora?

\begin{tabular}{|l|l|l|l|l|}
\hline Muito Melhor & Um Pouco Melhor & Quase a Mesma & Um Pouco Pior & Muito Pior \\
\hline 1 & 2 & 3 & 4 & 5 \\
\hline
\end{tabular}

3- Os seguintes itens são sobre atividades que você poderia fazer atualmente durante um dia comum. Devido à sua saúde, você teria dificuldade para fazer estas atividades? Neste caso, quando?

\begin{tabular}{|l|l|l|l|}
\hline Atividades & Sim, dificulta muito & $\begin{array}{l}\text { Sim, dificulta um } \\
\text { pouco }\end{array}$ & $\begin{array}{l}\text { Não, não dificulta de } \\
\text { modo algum }\end{array}$ \\
\hline $\begin{array}{l}\text { a) Atividades Rigorosas, que exigem muito esforço, tais como } \\
\text { correr, levantar objetos pesados, participar em esportes } \\
\text { árduos. }\end{array}$ & 1 & 2 & 3 \\
\hline $\begin{array}{l}\text { b) Atividades moderadas, tais como mover uma mesa, passar } \\
\text { aspirador de pó, jogar bola, varrer a casa. }\end{array}$ & 1 & 2 & 3 \\
\hline c) Levantar ou carregar mantimentos & 1 & 2 & 3 \\
\hline d) Subir vários lances de escada & 1 & 2 & 3 \\
\hline e) Subir um lance de escada & 1 & 2 & 3 \\
\hline f) Curvar-se, ajoelhar-se ou dobrar-se & 1 & 2 & 3 \\
\hline g) Andar mais de 1 quilômetro & 1 & 2 & 3 \\
\hline h) Andar vários quarteirões & 1 & 2 & 3 \\
\hline i) Andar um quarteirão & 1 & 2 & 3 \\
\hline j) Tomar banho ou vestir-se & 1 & 2 & 3 \\
\hline
\end{tabular}

4- Durante as últimas 4 semanas, você teve algum dos seguintes problemas com seu trabalho ou com alguma atividade regular, como consequência de sua saúde física?

\begin{tabular}{|l|l|l|}
\hline & Sim & Não \\
\hline a) Você diminui a quantidade de tempo que se dedicava ao seu trabalho ou a outras atividades? & 1 & 2 \\
\hline b) Realizou menos tarefas do que você gostaria? & 1 & 2 \\
\hline c) Esteve limitado no seu tipo de trabalho ou a outras atividades. & 1 & 2 \\
\hline $\begin{array}{l}\text { d) Teve dificuldade de fazer seu trabalho ou outras atividades (p. ex. necessitou de um esforço } \\
\text { extra). }\end{array}$ & 1 & 2 \\
\hline
\end{tabular}

5- Durante as últimas 4 semanas, você teve algum dos seguintes problemas com seu trabalho ou outra atividade regular diária, como consequência de algum problema emocional (como se sentir deprimido ou ansioso)?

\begin{tabular}{|l|l|l|}
\hline & $\operatorname{Sim}$ & Não \\
\hline a) Você diminui a quantidade de tempo que se dedicava ao seu trabalho ou a outras atividades? & 1 & 2 \\
\hline
\end{tabular}


b) Realizou menos tarefas do que você gostaria?

c) Não realizou ou fez qualquer das atividades com tanto cuidado como geralmente faz.

\begin{tabular}{|l|l|}
\hline 1 & 2 \\
\hline 1 & 2 \\
\hline
\end{tabular}

6- Durante as últimas 4 semanas, de que maneira sua saúde física ou problemas emocionais interferiram nas suas atividades sociais normais, em relação à família, amigos ou em grupo?

\begin{tabular}{|l|l|l|l|l|}
\hline De forma nenhuma & Ligeiramente & Moderadamente & Bastante & Extremamente \\
\hline 1 & 2 & 3 & 4 & 5 \\
\hline
\end{tabular}

7- Quanta dor no corpo você teve durante as últimas 4 semanas?

\begin{tabular}{|l|l|l|l|l|l|}
\hline Nenhuma & Muito leve & Leve & Moderada & Grave & Muito grave \\
\hline 1 & 2 & 3 & 4 & 5 & 6 \\
\hline
\end{tabular}

8- Durante as últimas 4 semanas, quanto a dor interferiu com seu trabalho normal (incluindo o trabalho dentro de casa)?

\begin{tabular}{|l|l|l|l|l|}
\hline De maneira alguma & Um pouco & Moderadamente & Bastante & Extremamente \\
\hline 1 & 2 & 3 & 4 & 5 \\
\hline
\end{tabular}

9- Estas questões são sobre como você se sente e como tudo tem acontecido com você durante as últimas 4 semanas. Para cada questão, por favor, dê uma resposta que mais se aproxime de maneira como você se sente, em relação às últimas 4 semanas.

\begin{tabular}{|c|c|c|c|c|c|c|}
\hline & \begin{tabular}{|l|} 
Todo \\
Tempo \\
\end{tabular} & $\begin{array}{l}\text { A maior parte } \\
\text { do tempo }\end{array}$ & \begin{tabular}{|l|} 
Uma boa parte \\
do tempo
\end{tabular} & $\begin{array}{l}\text { Alguma parte } \\
\text { do tempo }\end{array}$ & $\begin{array}{l}\text { Uma pequena } \\
\text { parte do tempo }\end{array}$ & Nunca \\
\hline $\begin{array}{l}\text { a) Quanto tempo você tem se sentindo } \\
\text { cheio de vigor, de vontade, de força? }\end{array}$ & 1 & 2 & 3 & 4 & 5 & 6 \\
\hline $\begin{array}{l}\text { b) Quanto tempo você tem se sentido } \\
\text { uma pessoa muito nervosa? }\end{array}$ & 1 & 2 & 3 & 4 & 5 & 6 \\
\hline $\begin{array}{l}\text { c) Quanto tempo você tem se sentido } \\
\text { tão deprimido que nada pode anima- } \\
\text { lo? }\end{array}$ & 1 & 2 & 3 & 4 & 5 & 6 \\
\hline $\begin{array}{l}\text { d) Quanto tempo você tem se sentido } \\
\text { calmo ou tranquilo? }\end{array}$ & 1 & 2 & 3 & 4 & 5 & 6 \\
\hline $\begin{array}{l}\text { e) Quanto tempo você tem se sentido } \\
\text { com muita energia? }\end{array}$ & 1 & 2 & 3 & 4 & 5 & 6 \\
\hline $\begin{array}{l}\text { f) Quanto tempo você tem se sentido } \\
\text { desanimado ou abatido? }\end{array}$ & 1 & 2 & 3 & 4 & 5 & 6 \\
\hline $\begin{array}{l}\text { g) Quanto tempo você tem se sentido } \\
\text { esgotado? }\end{array}$ & 1 & 2 & 3 & 4 & 5 & 6 \\
\hline $\begin{array}{l}\text { h) Quanto tempo você tem se sentido } \\
\text { uma pessoa feliz? }\end{array}$ & 1 & 2 & 3 & 4 & 5 & 6 \\
\hline $\begin{array}{l}\text { i) Quanto tempo você tem se sentido } \\
\text { cansado? }\end{array}$ & 1 & 2 & 3 & 4 & 5 & 6 \\
\hline
\end{tabular}

10- Durante as últimas 4 semanas, quanto de seu tempo à sua saúde física ou problemas emocionais interferiram com as suas atividades sociais (como visitar amigos, parentes, etc.)?

\begin{tabular}{|l|l|l|l|l|}
\hline Todo Tempo & A maior parte do tempo & Alguma parte do tempo & $\begin{array}{l}\text { Uma pequena parte do } \\
\text { tempo }\end{array}$ & $\begin{array}{l}\text { Nenhuma parte do } \\
\text { tempo }\end{array}$ \\
\hline 1 & 2 & 3 & 4 & 5 \\
\hline
\end{tabular}

\section{1- O quanto verdadeiro ou falso é cada uma das afirmações para você?}

\begin{tabular}{|l|l|l|l|l|l|}
\hline & $\begin{array}{l}\text { Definitivamente } \\
\text { verdadeiro }\end{array}$ & $\begin{array}{l}\text { A maioria das vezes } \\
\text { verdadeiro }\end{array}$ & $\begin{array}{l}\text { Não } \\
\text { sei }\end{array}$ & $\begin{array}{l}\text { A maioria das } \\
\text { vezes falso }\end{array}$ & $\begin{array}{l}\text { Definitiva- } \\
\text { mente falso }\end{array}$ \\
\hline $\begin{array}{l}\text { a) Eu costumo obedecer um pouco mais } \\
\text { facilmente que as outras pessoas }\end{array}$ & 1 & 2 & 3 & 4 & 5 \\
\hline $\begin{array}{l}\text { b) Eu sou tão saudável quanto qualquer } \\
\text { pessoa que eu conheço }\end{array}$ & 1 & 2 & 3 & 4 & 5 \\
\hline c) Eu acho que a minha saúde vai piorar & 1 & 2 & 3 & 4 & 5 \\
\hline d) Minha saúde é excelente & 1 & 2 & 3 & 4 & 5 \\
\hline
\end{tabular}

O SF-36 é um instrumento multidimensional que tem como finalidade avaliar, de forma genérica, o nível de qualidade de vida, englobando aspectos negativos da saúde (doença ou enfermidade) e aspectos 
positivos (bem-estar), sem possuir conceitos específicos para determinada idade, doença ou grupo de tratamento. É constituído por 36 itens englobados em 8 escalas ou domínios, assim distribuídos: Capacidade Funcional (dez itens), Aspectos Físicos (quatro itens), Dor (dois itens), Estado Geral de Saúde (cinco itens), Vitalidade (quatro itens), Aspectos Sociais (dois itens), Aspectos Emocionais (três itens), Saúde Mental (cinco itens) e uma questão que permite comparar as condições de saúde atual e de um ano atrás, mas que não é empregada no cálculo das escalas.

O tempo médio para preenchimento do SF-36 varia de 5 a 10 minutos. Para avaliação do resultado, é dado um escore para cada domínio visando transformá-lo numa escala graduada que varia de 0 a 100, em que zero (0) corresponde a um pior estado de saúde e cem (100) a um melhor estado. Para evitar o erro de não identificar ou subestimar os verdadeiros problemas relacionados à saúde do sujeito investigado, não existe um único valor que resuma toda a avaliação, ou seja, os resultados são apresentados por domínios.

Após a coleta, os dados foram submetidos à tabulação e à análise com a utilização do Excel, versão 2010. Para análise, utilizou-se a estatística descritiva, com a apresentação de frequência, média e desvio padrão. Os resultados foram apresentados por meio de gráficos e tabelas, de modo a facilitar a compreensão do fenômeno investigado.

\section{RESULTADOS E DISCUSSÃO}

Dos 79 docentes investigados, 55,7\% ( $n=44)$ eram do sexo masculino e $44,3 \%(n=34)$ do sexo feminino. Quanto ao estado civil, a maior parte dos respondentes, 58,2\% $(n=46)$ declarou-se casada, seguida por $21,5 \%(n=17)$ união estável, $16,5 \%(n=13)$ solteiro e 3,8\% ( $n=3)$ separado/divorciado. A tabela 1 apresenta a distribuição dos professores em relação à faixa etária.

Tabela 1: Distribuição dos docentes por faixa etária.

\begin{tabular}{l|l|l}
\hline Faixa Etária & $\mathbf{N}$ & $\mathbf{\%}$ \\
\hline Menos de 26 anos & - & - \\
\hline Entre 26-35 anos & 15 & 19 \\
\hline Entre 36-45 anos & 29 & 36,7 \\
\hline Entre 46-55 anos & 14 & 17,7 \\
\hline Entre 56-65 anos & 15 & 19 \\
\hline Acima de 65 anos & 06 & 7,6 \\
\hline
\end{tabular}

Quanto à titulação, a maioria, $45,6 \%(n=35)$ possui mestrado, $22,8 \%(n=18)$, doutorado, $21,5 \%(n=$ 17) pós-graduação latu sensu, $5,1 \%(n=4)$ pós-doutorado e $5,1 \%(n=4)$ somente graduação. $31,6 \%(n=25)$ dos docentes atuam entre 05-09 anos na instituição pesquisada, 26,6\% $(n=21)$ entre 01-04 anos, 8,9\% $(n=7)$ entre 15-19 anos, 7,6\% ( $n=6)$ entre 10-14 anos, sendo igual o quantitativo dos que atuam entre 01-04 anos e mais de 20 anos, $12,7 \%(n=10)$.

Em relação à carga horária de atuação dos professores no centro universitário investigado, observou a seguinte distribuição: $44,3 \%(n=35)$ menos de 20 h semanais, 30,4\% ( $n=24)$ entre $20-30$ h semanais, $17,7 \%$ $(n=14)$ entre $30-40 h$ semanais e $7,6 \%(n=6)$ acima de 40 h semanais, sendo que $68,4 \%(n=54)$ disseram atuar profissionalmente apenas na instituição, contra 31,6\% $(n=25)$ que afirmaram acumular vínculo empregatício em outras organizações de ensino. 
Dos respondentes, 63,3\% $(n=50)$ lecionam nas modalidades presencial e a distância $(\operatorname{EaD}), 35,4 \%(n=$ 28) apenas na modalidade presencial e 1,3\% $(n=1)$ somente na modalidade EaD. Quanto à área de conhecimento de atuação dos docentes, verificou-se a seguinte distribuição: $73,4 \%$ ( $n=58)$ ciências da saúde, 5,1\% $(n=4)$ ciências sociais aplicadas, 2,5\% $(n=2)$ ciências agrárias, $1,3 \%(n=1)$ engenharias e 8,9\% $(n=7)$ para ciências biológicas e ciências humanas.

No que se refere à percepção, de modo geral, que os professores afirmaram possuir sobre seus níveis de qualidade de vida, verificou-se que 59,49\% ( $n=47)$ os classificou como 'bom', $24,05 \%$ ( $n=19)$ como 'ótimo', 8,86\% ( $n=7)$ como 'excelente', 6,32\% $(n=5)$ como 'regular' e 1,26 (n= 1) como 'ruim'. A classificação 'péssimo' não foi citada por nenhum docente.

O Questionário SF-36 possibilita, por meio da questão de número 2, uma comparação entre as condições de saúde atual e de um ano atrás, a qual não é considerada no cálculo dos domínios. 0 gráfico 1 ilustra, sob a ótica dos docentes, a forma como se deu essa evolução, sendo que para a maioria, 53,16\% ( $n=$ 42), as condições de saúde permaneceram quase a mesma em relação ao ano anterior. No entanto, vale destacar que entre os professores que atuam simultaneamente nas modalidades presencial e EaD, 36\% ( $n=$ 18) afirmaram que as condições de saúde atual estão um pouco piores quando comparadas há um ano, o que demonstra uma possível precarização do estado de saúde desses profissionais ao longo do tempo.

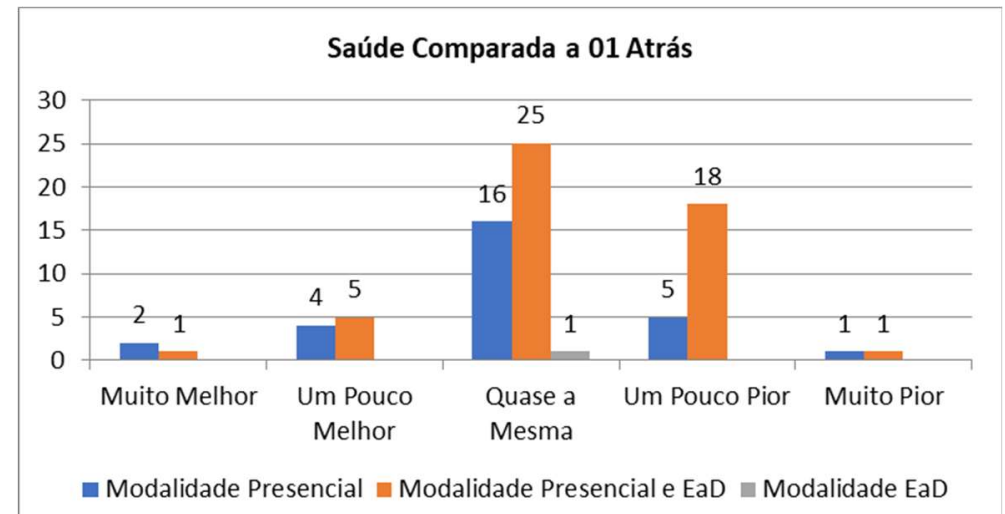

Gráfico 1: Condições de saúde atual comparada a 01 ano atrás.

Os resultados referentes à avaliação do nível de qualidade de vida dos docentes, por modalidade de ensino, estão descritos na tabela 2, que apresenta a média e o desvio padrão de cada domínio do SF-36. As tabelas 3, 4 e 5 apresentam, respectivamente, a frequência de domínios do SF-36 com escores inferiores (0 - 49), escores médios (50 - 74) e escores superiores (75 - 100) entre os professores pesquisados, por modalidade de ensino.

Tabela 2: Média e desvio padrão dos domínios SF-36 entre docentes por modalidade de ensino.

\begin{tabular}{|c|c|c|c|c|}
\hline \multirow{2}{*}{ DOMÍNIOS SF-36 } & \multicolumn{2}{|c|}{ Modalidade Presencial } & \multicolumn{2}{|c|}{ Modalidade Presencial e EaD } \\
\hline & Média & Desvio Padrão & Média & Desvio Padrão \\
\hline CAPACIDADE FUNCIONAL & 86,42 & 17,63 & 90,10 & 10,37 \\
\hline LIMITAÇÕES POR ASPECTOS FÍSICOS & 66,07 & 39,79 & 76,50 & 30,47 \\
\hline DOR & 70,67 & 25,80 & 76,62 & 21,03 \\
\hline ESTADO GERAL DE SAÚDE & 58,92 & 10,95 & 62,14 & 14,07 \\
\hline VITALIDADE & 55,53 & 21,05 & 56,60 & 19,65 \\
\hline ASPECTOS SOCIAIS & 70,98 & 22,83 & 65,25 & 27,35 \\
\hline LIMITAÇÕES POR ASPECTOS EMOCIONAIS & 72,61 & 39,60 & 59,33 & 40,00 \\
\hline SAÚDE MENTAL & 70,14 & 17,29 & 64,64 & 18,78 \\
\hline
\end{tabular}


Tabela 3: Frequência dos domínios SF-36 com escore inferior ( $0-49$ pontos).

\begin{tabular}{l|l|l|l|l}
\hline \multirow{2}{*}{ DOMÍNIOS SF-36 } & \multicolumn{2}{l}{ Modalidade Presencial } & \multicolumn{2}{l}{ Modalidade Presencial e EaD } \\
\cline { 2 - 5 } & $\mathbf{N}$ & $\mathbf{6}$ & $\mathbf{N}$ & $\%$ \\
\hline CAPACIDADE FUNCIONAL & 0 & 0 & 0 & 0 \\
\hline LIMITAÇÕES POR ASPECTOS FíSICOS & 7 & 25 & 8 & 16 \\
\hline DOR & 6 & 21,42 & 3 & 6 \\
\hline ESTADO GERAL DE SAÚDE & 7 & 25 & 10 & 20 \\
\hline VITALIDADE & 11 & 39,28 & 14 & 28 \\
\hline ASPECTOS SOCIAIS & 4 & 14,28 & 8 & 16 \\
\hline LIMITAÇÕES POR ASPECTOS EMOCIONAIS & 7 & 25 & 22 & 44 \\
\hline SAÚDE MENTAL & 3 & 10,71 & 11 & 22
\end{tabular}

Tabela 4: Frequência dos domínios SF-36 com escore médio (50 - 74 pontos).

\begin{tabular}{l|l|l|l|l}
\hline \multirow{2}{*}{ DOMÍNIOS SF-36 } & \multicolumn{2}{l}{ Modalidade Presencial } & \multicolumn{2}{l}{ Modalidade Presencial e EaD } \\
\cline { 2 - 5 } & $\mathbf{N}$ & $\mathbf{\%}$ & $\mathbf{N}$ & $\%$ \\
\hline CAPACIDADE FUNCIONAL & 7 & 25 & 4 & 8 \\
\hline LIMITAÇÕES POR ASPECTOS FíSICOS & 2 & 7,14 & 5 & 10 \\
\hline DOR & 10 & 35,71 & 19 & 38 \\
\hline ESTADO GERAL DE SAÚDE & 18 & 64,28 & 29 & 58 \\
\hline VITALIDADE & 8 & 28,57 & 25 & 50 \\
\hline ASPECTOS SOCIAIS & 10 & 35,71 & 16 & 32 \\
\hline LIMITAÇÕES POR ASPECTOS EMOCIONAIS & 4 & 14,28 & 7 & 14 \\
\hline SAÚDE MENTAL & 11 & 39,28 & 23 & 46
\end{tabular}

Tabela 5: Frequência dos domínios SF-36 com escore superior (75 - 100 pontos).

\begin{tabular}{l|l|l|l|l}
\hline \multirow{2}{*}{ DOMÍNIOS SF-36 } & \multicolumn{2}{l}{ Modalidade Presencial } & \multicolumn{2}{l}{ Modalidade Presencial e EaD } \\
\cline { 2 - 5 } & $\mathbf{N}$ & $\%$ & $\mathbf{N}$ & $\%$ \\
\hline CAPACIDADE FUNCIONAL & 21 & 75 & 46 & 92 \\
\hline LIMITAÇÕES POR ASPECTOS FÍSICOS & 19 & 67,85 & 37 & 74 \\
\hline DOR & 22 & 78,57 & 28 & 56 \\
\hline ESTADO GERAL DE SAÚDE & 3 & 10,71 & 11 & 22 \\
\hline VITALIDADE & 9 & 32,14 & 11 & 22 \\
\hline ASPECTOS SOCIAIS & 14 & 50 & 26 & 52 \\
\hline LIMITAÇÕES POR ASPECTOS EMOCIONAIS & 17 & 60,71 & 21 & 42 \\
\hline SAÚDE MENTAL & 14 & 50 & 16 & 32 \\
\hline
\end{tabular}

Devido ao fato de que apenas 1 professor respondente atua exclusivamente no ensino a distância, essa modalidade não foi inserida na apresentação e discussão dos resultados envolvendo o Questionário SF36.

Considerando os 8 fatores avaliados através do SF-36 (tabela 2), observa-se que o grupo de professores que atuam nas modalidades presencial e EaD possuem, de modo geral, maior número de domínios (5) com médias superiores aos que lecionam exclusivamente na modalidade presencial. Neste grupo, apenas os domínios Aspectos Sociais $(70,98)$, Limitações por Aspectos Emocionais $(72,61)$ e Saúde Mental $(70,14)$ possuem médias superiores àquelas identificadas entre os docentes das modalidades presencial e EaD, os quais, por sua vez, possuem os fatores Capacidade Funcional $(90,10)$, Limitações por Aspectos Físicos $(76,50)$, Dor $(76,62)$, Estado Geral de Saúde $(62,14)$ e Vitalidade $(56,60)$ com valores de médias superiores ao grupo que atua apenas na modalidade presencial (tabela 2).

Ao comparar os dois grupos de docentes (tabela 2), verifica-se que os domínios Aspectos Sociais, Limitações por Aspectos Emocionais e Saúde Mental apresentam valores elevados de médias entre aqueles que atuam apenas no ensino presencial. Diante desse resultado, pode-se inferir que há, entre os professores que lecionam em apenas uma modalidade de ensino, um número menor de cobranças, responsabilidades e tarefas, o que pode contribuir para elevar o nível de saúde mental e emocional, bem como ampliar as 
possibilidades de interações sociais desses profissionais.

Ao analisar o Estado Geral de Saúde dos grupos investigados, nota-se, conforme ilustra a tabela 2, uma diferença de 3,22 pontos entre as médias dos grupos, sendo maior o valor entre os docentes das modalidades presencial e $\operatorname{EaD}(62,14)$. A média dos dois grupos reflete um escore classificado como médio (50 - 74) para este domínio, sendo também maior a incidência de respostas nesta classificação entre os dois grupos (tabela 4).

Rocha et al. (2008) salientam que "a saúde dos trabalhadores é consequência da relação complexa e dinâmica entre o trabalhador e a sua atividade de trabalho". Um estado geral de saúde classificado como médio entre os professores pesquisados pode refletir as particularidades da profissão docente, reforçando o exposto pelos autores, o que aponta a necessidade de ações que modifiquem positivamente o cenário observado.

Quando se avalia a média geral de cada domínio em ambos os grupos (tabela 2), verifica-se a não ocorrência de valores inferiores a 49, considerado escore inferior (0 - 49). No entanto, a análise da tabela 3 permite identificar que entre os docentes existe a frequência de domínios nesta classificação, sendo a maior no fator Vitalidade (11) entre os que atuam apenas presencialmente. Já entre os professores que lecionam de forma presencial e a distância, destaca-se com maior frequência o domínio Limitações por Aspectos Emocionais (22), seguido por Vitalidade (14).

O domínio Vitalidade relaciona-se, segundo Ciconelli (1997), com o nível de energia e fadiga. É interessante observar que ao considerar as tabelas 3, 4 e 5, a maior incidência desse domínio entre docentes do ensino presencial ocorre na classificação inferior (0 - 49), tabela 3, com um quantitativo igual a 11. Já entre os professores das modalidades presencial e EaD, a maior incidência desse domínio é observada na classificação média (50 - 74), com uma frequência igual a 25 (tabela 4), embora também seja identificado 14 sujeitos deste grupo na classificação inferior (0 - 49), conforme tabela 3.

Entre o grupo de professores pesquisados, observa-se que o domínio Capacidade Funcional possui a maior média, sendo 86,42 naqueles que atuam na modalidade presencial e 90,10 nas modalidades presencial e EaD. Dos respondentes, nenhum possui esse fator classificado com escore inferior $(0-49)$, conforme tabela 3, verificando maior incidência na classificação superior $(75-100)$, como mostra a tabela 5.

Segundo Martins (2000), a capacidade funcional relaciona-se com a aptidão física, demostrando a capacidade que o indivíduo possui para realizar atividades diárias, resistir e superar os desafios e estresse. Os resultados obtidos apontam que os docentes investigados respondem de forma positiva aos desafios e estresse diário, fato importante diante das particularidades da profissão, que na maioria das vezes se desenvolve em um ambiente de desafio e estresse.

Quanto à Limitação por Aspectos Físicos, verifica-se que os professores que atuam nas modalidades presencial e EaD possui a melhor média $(76,50)$ quando comparados aos que lecionam apenas de forma presencial $(66,07)$, como exposto na tabela 2. A maior frequência desse domínio ocorre na classificação superior (75 - 100), em ambos os grupos (tabela 5). Quando se considera apenas o valor da média, observase que os docentes da modalidade presencial estão classificados como regular neste fator (tabela 2). 
A saúde física, de acordo com Rocha et al. (2008), quando se apresenta prejudicada pode refletir na prática docente, o que leva, segundo os autores, à possibilidade de um maior número de faltas ao trabalho, bem como maior desinteresse na realização e inovação da prática educacional. Portanto, para que o exercício docente seja eficaz, é condição sine qua non que os professores gozem de excelentes níveis de saúde física, a qual interfere de modo direto no nível de qualidade de vida desses profissionais.

No que se refere ao domínio Dor, presente no Questionário SF-36, verifica-se que este fator possui média de 70,67 entre docentes exclusivos da modalidade presencial e de 76,62 entre os da presencial e EaD (tabela 2), sendo a maior frequência na classificação considerada superior ( 75 - 100), conforme tabela 5.

Embora os valores de médias para este domínio possam ser considerados médio e superior, respectivamente, é importante destacar que em longo prazo a prática docente pode contribuir para a ocorrência de diversas patologias musculoesqueléticas e psicológicas, algumas associadas a quadros álgicos intensos, o que facilita o fenômeno do absenteísmo (SILVANY NETO et al., 2002; ZARAGOZA, 1999).

A média do domínio Limitações por Aspectos Emocionais é de 72,61 entre docentes do ensino presencial e de 59,33 entre os do presencial e EaD (tabela 2). No grupo dos professores da modalidade presencial, a maior frequência é observada na classificação superior (75-100), conforme tabela 5. Já entre o grupo que atua simultaneamente de forma presencial e EaD, a incidência na classificação inferior (0 - 49) e superior ( 75 - 100) se aproximam, com frequência de 22 e 21, respectivamente (tabelas 3 e 5).

Ao analisar o domínio Saúde Mental, observa-se média de 70,14 entre professores do ensino presencial e de 64,64 entre os das modalidades presencial e EaD (tabela 2). Entre o primeiro grupo, a maior frequência está na classificação superior (75 - 100), tabela 5; já no segundo, na classificação média (50 - 74), tabela 4.

Tanto o fator Limitações por Aspectos Emocionais quanto o fator Saúde Mental se apresentam com médias inferiores no grupo de docentes que atuam nas modalidades presencial e EaD, quando comparados ao grupo que atua apenas de forma presencial (tabela 2). Esse resultado conduz à suposição de que professores com exercício em mais de uma modalidade de ensino tendem a apresentarem um nível de saúde mental e emocional menor do que aqueles que se dedicam apenas a uma modalidade.

Este achado deve ser avaliado com cautela, pois a atividade docente possui diversos estressores psicossociais, os quais se relacionam com a natureza da função, com o contexto institucional e social onde é desenvolvida (CARLOTTO, 2002). Ainda para a autora, a persistência desses estressores pode conduzir à Síndrome de Burnout, vinculada a situações laborais, caracterizada por constante e repetitiva pressão emocional. Quando acomete professores, essa síndrome afeta o ambiente educacional, o que prejudica, nas palavras de Carlotto (2002), a obtenção dos objetivos pedagógicos, além de ocasionar problemas de saúde, absenteísmo e o desejo de abandonar a profissão.

Em relação ao domínio Aspectos Sociais, este apresentou média de 70,98 entre os docentes da modalidade presencial e 65,25 entre os das modalidades presencial e EaD (tabela 2). Embora estes valores de médias estejam na classificação média (50 - 74), a maior incidência deste fator foi na classificação superior (75-100), conforme se observa na tabela 5. 
O domínio Aspectos Sociais reflete a interação com a família, amigos e com a comunidade (CICONELLI, 1997). Apesar da diferença entre as médias deste fator ser relativamente pequena entre os grupos de docentes investigados $(5,73)$, tabela 2, esperava-se encontrar valores menores entre os professores que lecionam nas modalidades presencial e EaD, uma vez que a atuação docente em mais de uma modalidade apresenta-se intensificada, expondo estes profissionais a uma carga de trabalho maior, o que reduz a interação social.

É importante destacar que a avaliação do domínio Aspectos Sociais deve ser realizada com ponderação, já que a coleta de dados ocorreu em um período marcado pela pandemia da COVID-19, no qual as recomendações sanitárias eram o isolamento e o distanciamento social, fator que pode ter exercido influência no resultado deste domínio que avalia a interação social entre os sujeitos. Contudo, mesmo diante desse cenário de isolamento, os valores de médias identificados no fator Aspectos Sociais podem ser considerados satisfatórios, principalmente quando se observa, em ambos os grupos, uma maior incidência desse domínio na classificação superior (75 - 100), como observado na tabela 5.

De início, estabeleceu-se a hipótese de que professores que atuam simultaneamente nas modalidades presencial e EAD possuem nível de qualidade de vida, em geral, menor do que aqueles que lecionam apenas em uma modalidade (presencial ou EAD). Isso porque a carga horária, tarefas, dedicação e outros fatores inerentes à profissão seriam maiores para aqueles que trabalham em mais de uma modalidade de ensino. No entanto, os resultados observados não permitem afirmar qual grupo possui o melhor nível de qualidade de vida, devido ao fato de que o Questionário SF-36 não gera uma avaliação global, mas sim a situação do indivíduo em cada domínio investigado. Diante dessa especificidade do instrumento, apenas verificou-se, de modo geral, que docentes que atuam nas modalidades presencial e EaD possuem maior número de domínios do SF-36 bem mais avaliados quando comparados com aqueles que lecionam apenas no EaD, o que sinaliza um melhor estado de saúde entre os profissionais que trabalham em ambas as modalidades de ensino.

\section{CONCLUSÕES}

Para compreender o nível de qualidade de vida de um indivíduo, faz-se necessário conhecê-lo em sua totalidade, avaliando fatores internos e externos que atuam sobre o sujeito. Neste sentido, a variável trabalho exerce grande influência, pois em alguns casos relaciona-se intrinsicamente com a identidade do ser, como ocorre no trabalho docente.

Este estudo observacional, descritivo, de corte transversal e abordagem quantitativa, realizado em uma instituição de ensino superior privada localizada no município de Valença-RJ, teve como objetivo identificar o nível de qualidade de vida de docentes de diferentes modalidades e propor ações que potencializem a promoção da saúde desses profissionais.

A amostra foi composta por 79 docentes, sendo que 50 afirmaram lecionar nas modalidades presencial e EaD, 28 apenas na modalidade presencial e 01 na modalidade EaD. Quanto à caracterização dos sujeitos, prevalece o sexo masculino, o estado civil casado e a faixa etária de 36-45 anos. Em termos de 
profissão, a maioria possui mestrado, atua entre 05-09 anos na instituição, cumpre carga horária de menos de $20 \mathrm{~h}$ semanais, trabalha exclusivamente no centro universitário pesquisado e pertence à área de ciências da saúde. Quanto à percepção em relação ao nível de qualidade de vida, de modo geral, a maior parte dos professores disse considerá-lo 'bom'. Quanto às condições de saúde, a maioria afirmou que estas permanecem quase a mesma quando comparadas há um ano.

A análise do nível de qualidade de vida foi realizada por meio da versão brasileira do Questionário de Qualidade de Vida SF-36, composto por oito fatores/domínios, que recebem escores que variam de 0 a 100, em que zero (0) corresponde a um pior estado de saúde e cem (100) a um melhor estado. Os resultados observados indicam que os docentes que atuam na modalidade presencial e EaD possuem os domínios Capacidade Funcional, Limitações por Aspectos Físicos, Dor, Estado Geral de Saúde e Vitalidade com médias superiores àqueles que lecionam exclusivamente na modalidade presencial, os quais, por sua vez, apresentam os fatores Aspectos Sociais, Limitações por Aspectos Emocionais e Saúde Mental com valores de médias superiores quando comparado os dois grupos, o que sugere um melhor estado de saúde entre os professores que trabalham simultaneamente nas modalidades presencial e EaD.

Os resultados encontrados não permitem apontar qual grupo de docentes possui melhor nível de qualidade de vida, comparando as modalidades de ensino, apenas identificar a situação dos grupos em cada domínio do SF-36. Ademais, devido ao fato de que apenas um professor atuava exclusivamente no ensino a distância, esta modalidade não foi considerada na análise dos dados.

Diante dos resultados verificados, algumas intervenções podem ser desenvolvidas pela instituição, de modo a potencializar o nível de qualidade de vida dos docentes investigados. Uma ação que pode ser adotada e possui resultados positivos comprovados em relação à melhoria do nível de qualidade de vida é o incentivo à prática de atividades físicas. Para isso, o centro universitário pode estabelecer parcerias com academias localizadas na cidade de Valença/RJ, de modo que estas ofereçam descontos e pacotes promocionais aos docentes, o que incentivará a prática do exercício físico.

Outra sugestão é a realização de eventos culturais na organização, bem como a oferta de ingressos para casas de shows e cinema localizados na cidade. Essas ações possuem a capacidade de abranger os domínios aspectos sociais e saúde mental, com comprovada influência no nível de qualidade de vida.

O cuidado com a saúde e questões ergonômicas também deve ser considerado. Para tanto, a instituição pode realizar palestras em intervalos regulares para abordar assuntos como cuidados com a saúde física e mental, alimentação, ergonomia no trabalho, ginástica laboral, dentre outros. Ademais, deve-se atentar para o ambiente de trabalho dos docentes, verificando, por exemplo, disposição de equipamentos em salas de aula, iluminação, recursos tecnológicos apropriados, climatização, acesso à local de descanso e à alimentação, quando necessários.

Além dessas recomendações, a empresa deve manter e incentivar um ambiente no qual o clima organizacional favoreça a interação e a troca entre os professores, bem como possuir um canal de diálogo aberto entre estes profissionais e o setor de recursos humanos, de modo a identificar e solucionar as demandas relacionadas à qualidade de vida que por ventura possam surgir. 
Vale ressaltar que o presente estudo possui algumas limitações. A primeira, refere-se à ausência de uma amostra representativa do grupo de professores que atuam exclusivamente na modalidade $\mathrm{EaD}$, o que impossibilitou a comparação dos resultados entre diferentes modalidades de ensino. Segundo, a forma como o convite para participar do estudo foi realizada, o que pode ter prejudicado na obtenção de um número maior de respondentes.

Em estudos futuros, sugere-se a adoção de uma abordagem diferenciada dos sujeitos, de modo a obter uma amostra maior, que abranja todas as modalidades de ensino. Ademais, utilizar outros instrumentos para avaliar o nível de qualidade de vida dos docentes, realizando comparações com os resultados obtidos por meio do Questionário SF-36, assim como a aplicação da estatística inferencial para verificar a existência ou não de relações entre modalidades de ensino e nível de qualidade de vida dos professores.

\section{REFERÊNCIAS}

ARAÚJO, A. L.; FÉ, E. M.; ARAÚJO, D. A. M.; OLIVEIRA, E. S.; MOURA, I. H.; SILVA, A. R. V.. Avaliação da qualidade de vida no trabalho de docentes. Revista de Enfermagem do Centro-Oeste Mineiro, v.9, p.1-8, 2019. DOI: https://doi.org/10.19175/recom.v9i0.3195

BOSI, A. P.. A precarização do trabalho docente nas instituições de ensino superior do Brasil nesses últimos 25 anos. Educação \& Sociedade, Campinas, v.28, n.101, p.15031523, 2007. DOI: https://doi.org/10.1590/S010173302007000400012

CARLOTTO, M. S.. A síndrome de Burnout e o trabalho docente. Psicologia em Estudo, Maringá, v.7, n.1, p.21-29, 2002.

CHIAVENATO, I.. Recursos Humanos: o capital humano das organizações. 10 ed. Rio de Janeiro: Elsevier, 2015.

CICONELLI, R. M.. Tradução para o português e validação do questionário genérico de avaliação de qualidade de vida "Medical Outcomes Study 36-Item Short-Form Health Survey (SF-36)". Tese (Doutorado em Medicina) Universidade Federal de São Paulo, São Paulo, 1997.

CURY JUNIOR, C. H.. Qualidade de vida no trabalho e subjetividades docentes. Evidência, Araxá, n.6, p.89-110, 2010.

DEJOURS, C.. A loucura do trabalho: estudo de psicopatologia do trabalho. 5 ed. São Paulo: Cortez, 1992.

FERREIRA, A. C; PASSOS, J. C.. Um olhar sobre a qualidade de vida no trabalho do professor de Ciências Contábeis: o caso de uma universidade federal mineira. In: CONGRESSO UFU DE CONTABILIDADE, 1. Anais. Uberlândia, 2015. p.1-21.

GIL, A. C.. Como elaborar projetos de pesquisa. 6 ed. São Paulo: Atlas, 2018.

GOMES, K. K.; SANCHEZ, H. M.; SANCHEZ, E. G. M.; SBROGGIO JÚNIOR. A. L.; ARANTES FILHO, W. M.; SILVA, L. A.; BARBOSA, M. A.; PORTO, C. C.. Qualidade de vida e qualidade de vida no trabalho em docentes da saúde de uma instituição de ensino superior. Revista Brasileira de Medicina do Trabalho, São Paulo, v.15, n.1, p.18-28, 2017. DOI: https://doi.org/10.5327/Z1679443520177027

HOCHMAN, B.; NAHAS, F. X.; OLIVEIRA FILHO, R. S.; FERREIRA, L. M.. Desenhos de pesquisa. Acta Cirúrgica Brasileira, São Paulo, v.20, n.2, p.2-9, 2005. DOI: https://doi.org/10.1590/S0102-86502005000800002

LIMA, M. F. E. M.; LIMA FILHO, D. O.. Condições de trabalho e saúde do/a professor/a universitário/a. Ciências \& Cognição, v.14, n.3, p.62-82, 2009.

MATIAS-PEREIRA, J.. Manual de metodologia da pesquisa científica. 3 ed. São Paulo: Atlas, 2012.

MATTOS, C. A. C.; DAMASCENO, V. B.; GAMA, M. C. F.; SIMÃO, C. S.; COSTA, N. L.. Qualidade de vida no trabalho: uma investigação multivariada entre docentes. Revista Raunp, v.10, n.1, p.77-91, 2017. DOI: http://dx.doi.org/10.21714/raunp.v10i1.1782

MINAYO, M. C. S; HARTZ, Z. A.; BUSS, P. M.. Qualidade de vida e saúde: um debate necessário. Ciência \& Saúde Coletiva, Rio de Janeiro, v.5, n.1, p.7-18, 2000. DOI: https://doi.org/10.1590/S1413-81232000000100002

PEREIRA, E. F.; TEIXEIRA, C. F.; SANTOS, A.. Qualidade de Vida: abordagens, conceitos e avaliação. Revista Brasileira de Educação Física e Esporte, São Paulo, v.26, n.2, p.241-50, 2012. DOI: https://doi.org/10.1590/S180755092012000200007

PEREIRA, O. A. V.. Qualidade de vida no trabalho de docentes universitários de uma instituição pública e outra privada do leste de Minas Gerais. Dissertação (Mestrado em Meio Ambiente e Sustentabilidade) - Centro Universitário de Caratinga, Caratinga, 2006.

RÊGO, A. D.; OLIVEIRA, A. L.. Qualidade de vida no trabalho de professores da educação: revisão integrativa. InterEspaço: Revista de Geografia e Interdisciplinaridade, Grajaú, v.11, n.3, p.375-388, 2017. DOI:

http://dx.doi.org/10.18764/2446-6549.v3n11p375-388 
REIS, B. M.. Trabalho docente e qualidade de vida. Revista Encontro de Pesquisa em Educação, Uberaba, v.1, n.1, p.3748, 2013.

ROCHA, V. M.; FERNANDES, M. H.. Qualidade de vida de professores do ensino fundamental: uma perspectiva para a promoção da saúde do trabalhador. Jornal Brasileiro de Psiquiatria, Rio de Janeiro, v.57, n.1, p.23-27, 2008. DOI: https://doi.org/10.1590/S0047-20852008000100005

SANCHEZ, H. M.; SANCHEZ, E. G. M.; BARBOSA, M. A.; GUIMARÃES, E. C.; PORTO, C. C.. Impacto da saúde na qualidade de vida e trabalho de docentes universitários de diferentes áreas de conhecimento. Ciência \& Saúde Coletiva, Rio de Janeiro, v.24, n.11, p.4111-4122, 2019. DOI: https://doi.org/10.1590/1413-812320182411.28712017

SILVANY NETO, A. M.; ARAÚJO, T. M.; DUTRA, F. R. D.; ALVES, R. L.; KAVALKIEVICS, C.; REIS, E. J. F. B.. Condições de trabalho e saúde de professores da rede particular de ensino de Salvador, Bahia. Revista Baiana de Saúde Pública, v.24, n.1-2, p.42-56, 2000. DOI: https://doi.org/10.22278/23182660.2000.v24.n1-2.a980

VASCONCELOS, P. H.; ALVES, C. E. L.; SANTOS, S. F. M.; FRANCISCO, A. C.. Qualidade de vida no trabalho docente: um estudo de caso em uma instituição de ensino superior. Revista de Administração e Inovação, São Paulo, v.9, n.2, p.79-97, 2012. DOI: https://doi.org/10.5773/rai.v9i2.696

WHO. World Health Organization. The World Health Organization Quality of Life assessment (WHOQOL): position paper from the World Health Organization.Social Science \& Medicine, v.41, n.10, p.1403-1409, 1995. DOI: https://doi.org/10.1016/0277-9536(95)00112-K

ZARAGOZA, J. M. E.. O mal-estar docente: a sala de aula e saúde dos professores. Bauru: Edusc, 1999.

A CBPC - Companhia Brasileira de Produção Científica (CNPJ: 11.221.422/0001-03) detém os direitos materiais desta publicação. Os direitos referem-se à publicação do trabalho em qualquer parte do mundo, incluindo os direitos às renovações, expansões e disseminações da contribuição, bem como outros direitos subsidiários. Todos os trabalhos publicados eletronicamente poderão posteriormente ser publicados em coletâneas impressas sob coordenação da Sustenere Publishing, da Companhia Brasileira de Produção Científica e seus parceiros autorizados. Os (as) autores (as) preservam os direitos autorais, mas não têm permissão para a publicação da contribuição em outro meio, impresso ou digital, em português ou em tradução. 